\title{
DEVELOPMENT OF AUTOMATED THREE-DIMENSIONAL WAREHOUSE MANAGEMENT SYSTEM
}

\author{
Deng Mingxing ${ }^{1}$, Wei Hongyuan ${ }^{2}$ \\ ${ }^{1}$ School of Mechanical Engineering, Shanghai University of Engineering Science, Shanghai201620, China \\ ${ }^{2}$ School of Mechanical Engineering, Shanghai University of Engineering Science, Shanghai201620, China
}

\begin{abstract}
In view of the current status of manual handling of off-line products and palletizing in the factory, the use of various AGV and warehouse management system software enables automatic entry and exit of offline products. The warehouse management system is compiled with C\#, MySQL, network communication technology, scheduling algorithm, etc. to realize the allocation of the warehouse goods and the intelligent distribution of the outbound goods. After the preparation, the warehouse management system can finally realize real-time communication with WCS, total control PLC, palletizer, etc., to realize the intelligent entry and exit of goods. Combined with a variety of AGVs, the warehouse management system can improve the management efficiency and management quality of goods, realize digital management, enhance the competitiveness of enterprises, and bring great economic benefits.
\end{abstract}

Keywords: - warehouse management system, C\#, C/S network architecture, network communication

\section{INTRODUCTION}

With the promotion of national strategic favorable policies such as "Internet +" and "Made in China 2025" and the increasing demand for informationization, efficient production and intensive warehousing and distribution, the automated warehousing system has been used more and more widely. Its fields of research are also expanding. [1] In recent years, China's express delivery industry has mushroomed like a mushroom, and more and more exports to foreign countries have greatly boosted China's economic growth. As a result, we are also facing new challenges. As demand grows, companies need to increase their production by increasing efficiency. As an important part of the express delivery industry, warehousing management can improve the management efficiency and management quality of finished goods storage, which can greatly reduce the problems caused by the traditional cargo backlog and other factors, and manage goods in the fastest and most optimal way. This will bring great economic benefits to the company.

In recent years, the automated three-dimensional warehouse has become a cargo storage solution applied by various enterprises. The automated three-dimensional warehouse can also be called an unmanned warehouse. The whole process is carried out by the AGV or the stacker to carry out the goods, which can reduce the number of traditionally The cost of manpower to carry goods. Automated warehouses have the characteristics of high degree of automation, energy saving, safety, intensive storage, high efficiency, and unattended [1]. As the core component of the automated warehouse, the WMS warehouse management system can optimize the distribution of goods entering and leaving the warehouse and track in real time. The warehouse status of the warehouse is also updated in real time as the goods enter and exit, realizing the automatic entry and exit of the goods and the record library. The function of the bit status. In addition, the WMS warehouse management system can provide warehouse managers with a visual location display, which allows warehouse managers to easily understand the location information and manage the warehouse accordingly.

In view of the many disadvantages of the existing offline product storage methods of the customer company, and the continuous pursuit of high efficiency, high quality and digital management, it is decided to adopt the automated warehouse solution to meet the storage and management requirements of the current goods.

\section{DEMAND AND SITE LAYOUT}

\subsection{Demand Analysis}

In order to reduce personnel, improve the efficiency of cargo palletizing, and realize digital management, the company proposes the plan of automated warehouse. It generally includes the following steps: 1 . The offline product is sent to the storage roller line by AGV; 2 . The product flows into the corresponding crossing through the roller line; 3 . The warehouse AGV sends the goods to assigned location which from WMS; 4 . The AGV sends the product to the exit of the warehouse; 5 . The palletizing machine palletizes the product that flows out of the unloading roller line, covers the cover, and then covers the film and the cable tie. 
According to the actual situation, the daily net storage of the three-dimensional warehouse is 2,500 boxes of goods. The goods entering the warehouse need to pass the quality inspection (OQC, Outgoing Quality Control), and the qualified goods can be assigned to the warehouse for palletizing. As the core part of the automated warehouse, WMS plays the role of data collection, data statistics, location allocation and information transmission.

\subsection{Site Layout}

The automated warehouse is mainly composed of six parts: shelves, containerized unit, conveyor system, automatic control system, and information management system (WMS). [1]

\subsubsection{Overall Layout of the Site}

The overall layout of the site consists of: the storage roller line, the three-dimensional warehouse, the outbound roller line, the palletizing machine, the film wrapping machine, and the board warehouse machine. The overall layout is shown in Fig- 2.1.

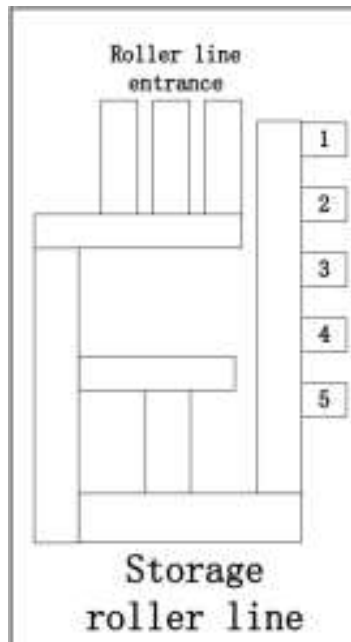

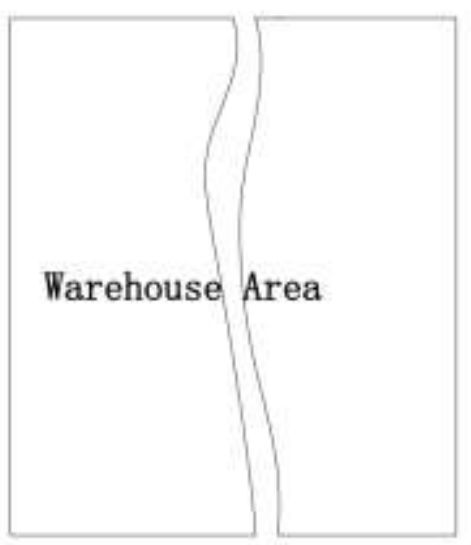

Fig 2.1: Overall layout

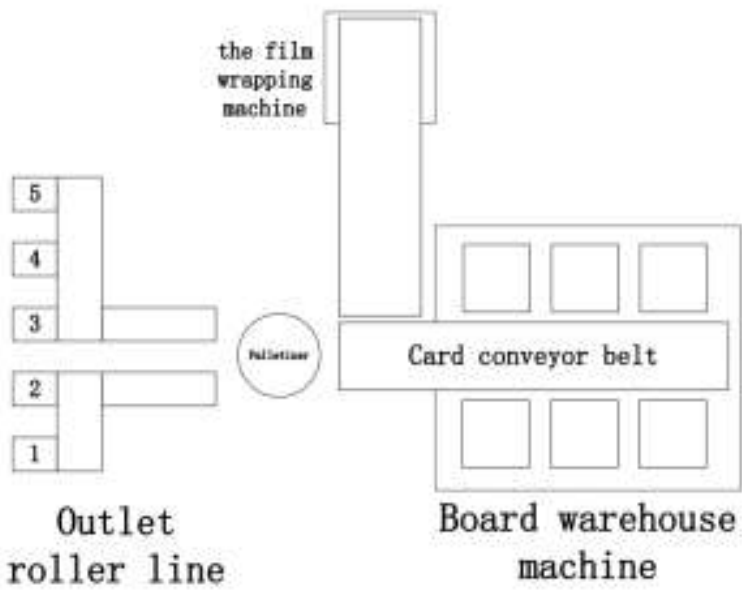

machine

\subsubsection{Warehouse Overall Layout and Location}

\section{Division}

According to the actual demand and on-site venue restrictions, the final number of warehouses determined by the three-dimensional warehouse is 2,640, divided into 24 areas, which are A X. The specific layout is shown in Fig- 2.2. 

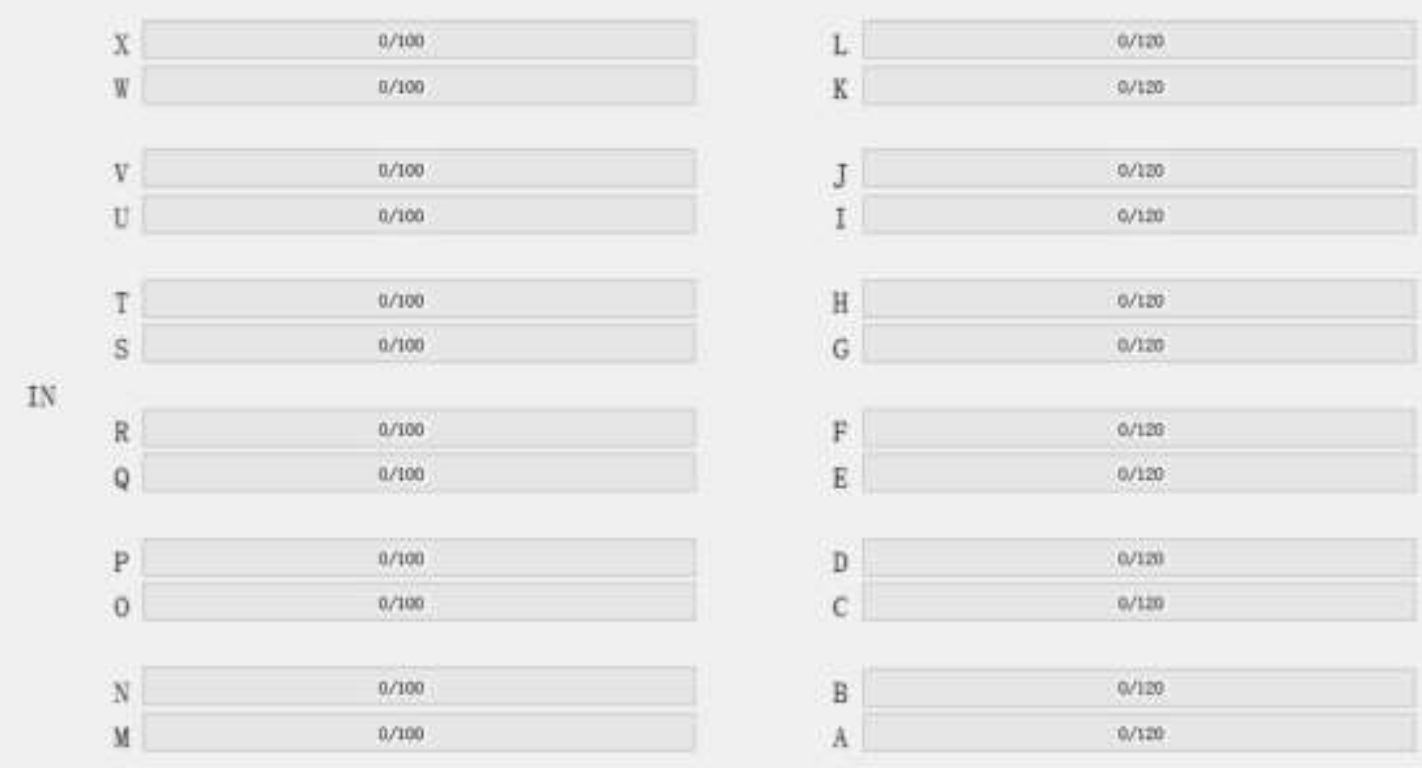

Fig 2.2: Top view of the warehouse layout

There are two types of shelf types: Class I includes A L library area, a total of twelve, each library area has 120 locations; Class II includes $\mathrm{M} \sim \mathrm{X}$ library areas, a total of twelve, each of which has 100 locations. The front view of the two types of shelves is shown in Fig- 2.3 and Fig- 2.4.

\begin{tabular}{|c|c|c|c|c|c|c|c|c|c|c|c|c|c|c|c|c|c|c|c|c|c|c|c|}
\hline$\therefore \mathrm{A}$ & & & & & & & & & & & & & & & & & & & & & - & 口 & X \\
\hline 1245 & 1236 & 1225 & 1215 & 1205 & A.95 & A:65 & A175 & A.65 & A.55 & N145 & N435 & A.25 & N.15 & A. 105 & 4095 & Noes & $N 075$ & 1065 & 1005 & 1045 & 1035 & N025 & 1015 \\
\hline 1244 & 1234 & A224 & N214 & 2204 & A.194 & ALA & A1 74 & k1 64 & AI54 & A. 144 & A 134 & A124 & A114 & A. 104 & 4094 & NoS4 & N074 & 1064 & WOSA & A044 & 1034 & NOS4 & 2014 \\
\hline 2043 & 1233 & 1223 & 1213 & 2003 & A 493 & Al63 & A173 & N.63 & A.63 & Al43 & $\alpha 133$ & ㄴ.23 & NA13 & A:03 & 1003 & N003 & 1073 & h083 & No63 & 4043 & 1033 & Nes & 1013 \\
\hline k242 & 1238 & 1222 & 1212 & 1200 & A. 192 & ALE2 & A1 72 & A. 62 & A.52 & At 42 & $M: 32$ & A.22 & N112 & $A: C 2$ & 4092 & Nose & A072 & 1062 & W52 & 1042 & 1032 & $\mathrm{NOC2}$ & 1012 \\
\hline k241 & N23t & A2.21 & Ne11 & 2001 & A.91 & A:81 & A17 & N161 & A.51 & Al41 & A. $13 \mathrm{t}$ & A121 & All1 & AlOt & \$. 091 & N2011 & AOn & No61 & No51 & A041 & A03! & Noer & A011 \\
\hline
\end{tabular}

Fig 2.3: Front view of the class I shelf

\begin{tabular}{|c|c|c|c|c|c|c|c|c|c|c|c|c|c|c|c|c|c|c|c|}
\hline$\Leftrightarrow M$ & & & & & & & & & & & & & & & & & - & ㅁ] & $x$ \\
\hline 005 & $\underline{\mathbf{p}}_{1905}$ & mis & $\mathrm{Mn} 75$ & M:65 & $\mathbf{Y}_{155}$ & $m 25$ & $\mathbf{1 1} 135$ & M125 & Mn15 & mos & 焉06 & 1005 & mo75 & 1005 & most & No45 & 10035 & wo25 & W015 \\
\hline reO4 & Y्र194 & mest & Yn174 & met & Y1154 & $\mathrm{M} 24$ & P134 & $\mathrm{m} 2 \mathrm{~s}$ & $\mathrm{H} 1 \mathrm{H}$ & Hot & $\mathbf{m} \times 4$ & wo64 & w014 & nDGA & w054 & mon & 1034 & Yo:4 & Y014 \\
\hline rew & Yn190 & mes & 표 & nes & Y153 & Now & ע1 & \$1123 & Mn13 & now & $\mathbf{1 0 9 3}$ & & woth & n063 & Y050 & 006 & 1003 & yos & \$01013 \\
\hline$n=0$ & mi92 & nee & $\boldsymbol{y}_{1}>72$ & $m=2$ & स152 & $3: 42$ & $\mathrm{u}_{1} 32$ & maz & Yn12 & noc & mos & $\mathrm{m}=02$ & wot2 & $n \in 62$ & Yo5: & $\$ 042$ & mose & Yon22 & $\underline{0012}$ \\
\hline Eot & $\mathbf{x}_{191}$ & m:at & Y:171 & m:6! & $\mathbf{P}_{151}$ & m:4! & $\mathbf{x}_{131}$ & M421 & n!11 & nol & mo1 & mo1 & $\mathbf{m} 71$ & mot & Yo5 & Do4 & most & 1021 & $\underline{x} 11$ \\
\hline
\end{tabular}

Fig 2.4: Front view of class II shelves 
According to the width of the location and the maximum height of the product, the location categories are divided into four categories: A, B, A1, and B1.

Class A locations are distributed in the 1-4 layers of the class I library area and the 1-4 layers of columns 1-8 of the class II library area, with a total of 1536 locations;

Class A1 locations are distributed in the 5th layer of the class I library area and the 5th layer of columns 1-8 of the class II library area, with a total of 384 locations;
Class B locations are distributed in the 1-4 layers of columns 9-20 of the class II library area, with a total of 576 locations;

Class B1 locations are distributed in the 5 layer of columns 9-20 of the class II library area, with a total of 144 locations.

The specific division of the warehouse location categories is shown in Fig- 2.5 and Fig- 2.6.

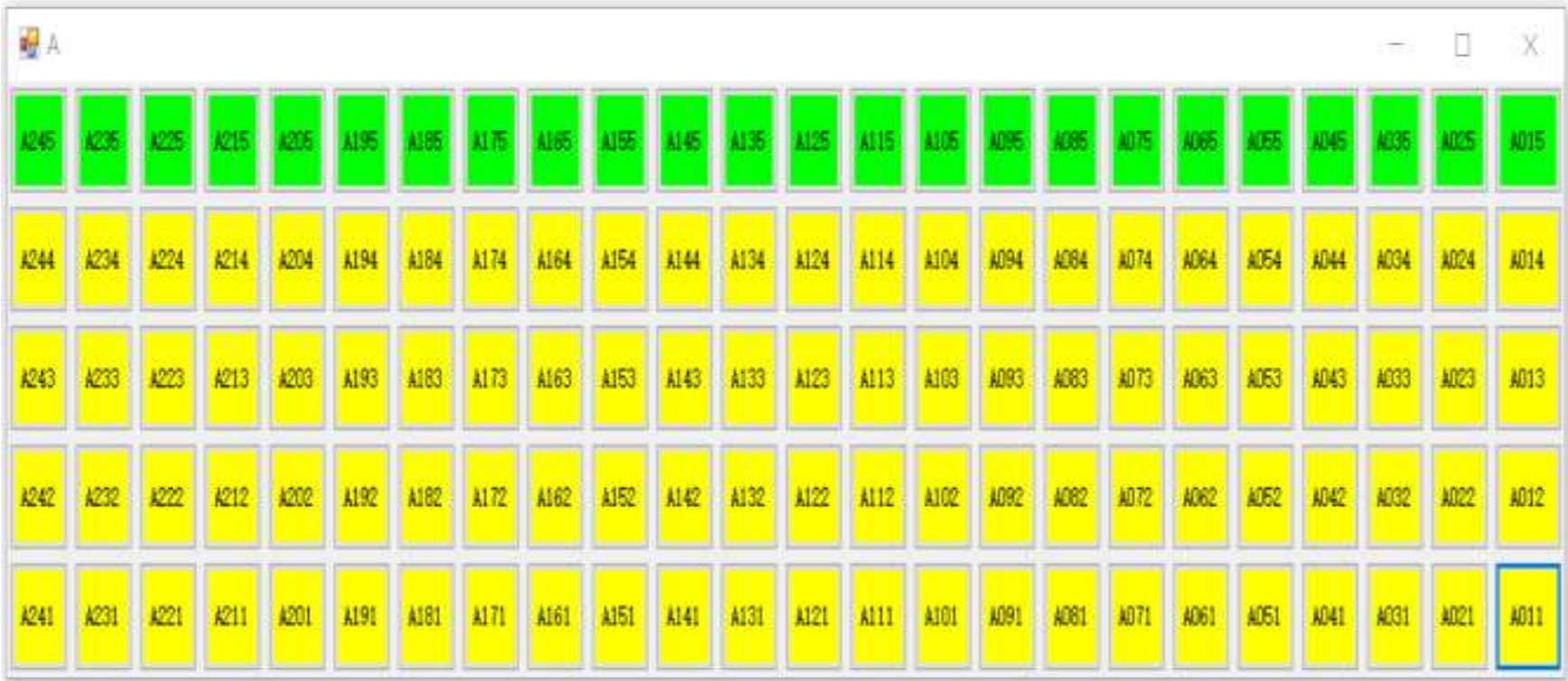

Fig 2.5: Class I Library Area Location Classification

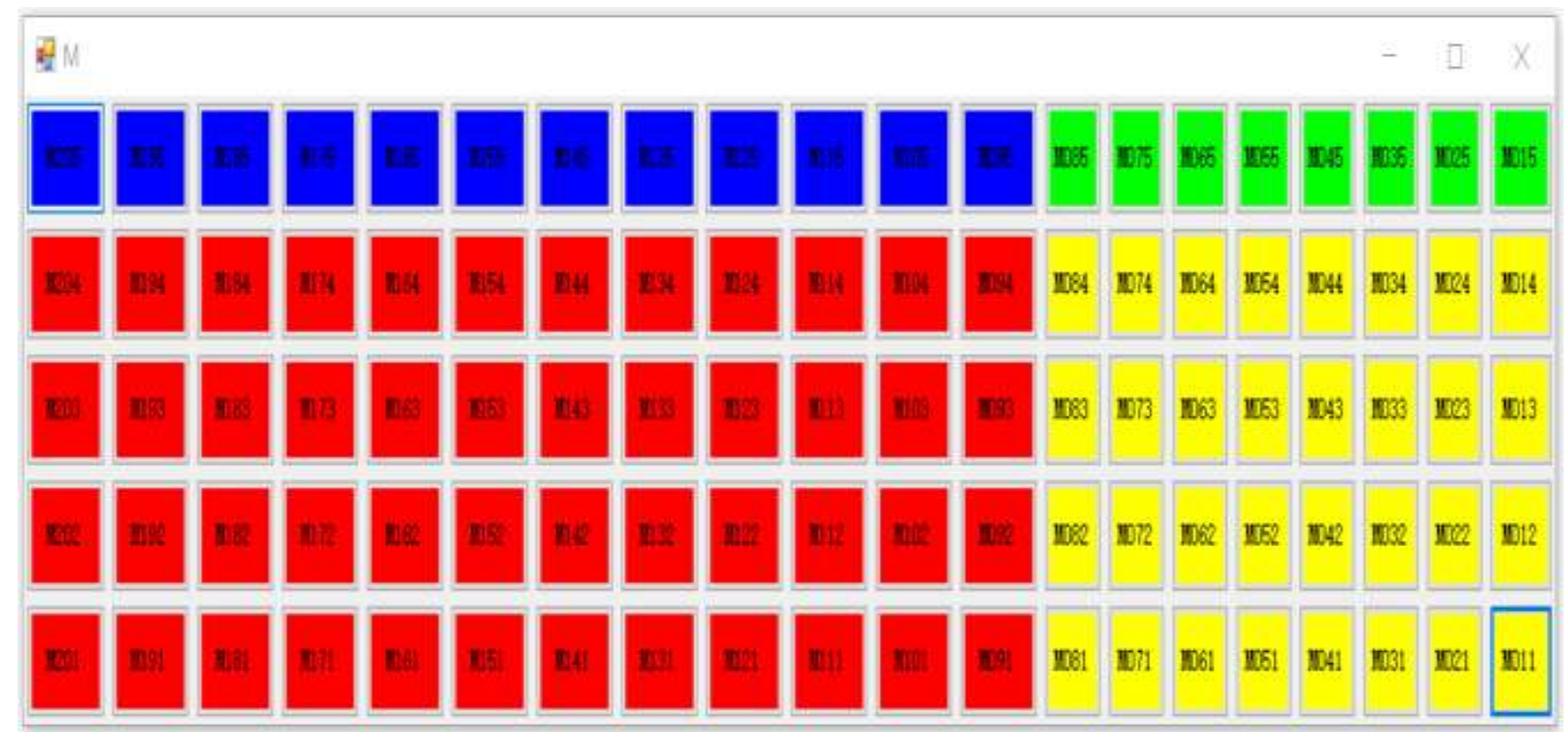

Fig 2.6: Class II Library Area Location Classification 
Description: Among them, yellow is the class A location, green is the A1 location, red is the B location, and blue is the B1 location.

\section{SOFTWARE DEVELOPMENT}

\subsection{System Network Architecture}

and

\section{Communication Content}

\subsubsection{WMS System Network Architecture}

Client-server model Also known as the client-server architecture, C/S architecture, is a network architecture that takes the client (usually a graphical user) The interface program is distinguished from the server. Each instance of the client software can make a request to a server or application server. [3] C/S is generally established on a dedicated network. In a small-scale network environment, LANs provide connection and data exchange services through dedicated servers. C/S generally targets a relatively fixed user base and has strong control over information security. Generally, the highly confidential information system adopts the C/S structure. [4] The field conditions and requirements are basically consistent with the $\mathrm{C} / \mathrm{S}$ characteristics, so the WMS adopts the $\mathrm{C} / \mathrm{S}$ network architecture.

According to the overall plan design of the three-dimensional warehouse, the network framework is built to realize data interaction, and then the normal operation of the three-dimensional warehouse is realized. The network architecture diagram is shown in Fig- 3.1.

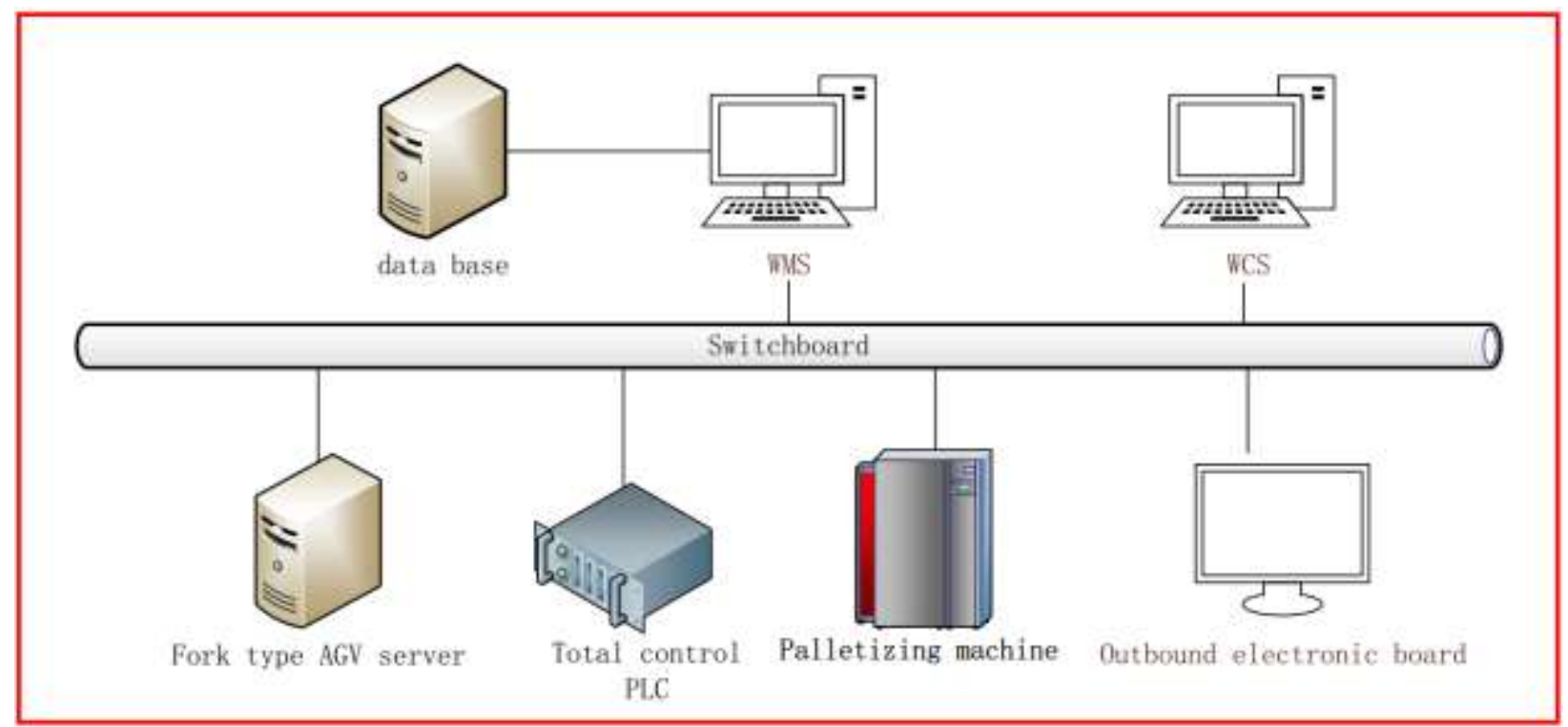

Fig 3.1: Network architecture diagram

\subsubsection{Communication between WMS and each} Module

The implementation of the WMS function mainly depends on: 1 . Communicating with the database; 2 . Communicating with each host computer (mainly including: WCS warehouse control system, total control PLC, fork-type AGV server, palletizer upper computer). The following mainly introduces the implementation of WMS and various communication modules and the role of communication information.

WMS communicates with the database: it mainly records the location of the product, the data pushed by the WCS, the planned warehousing model and its related requirements, and the task tracking generated by the AGVS communication.

WMS and WCS communication: Get daily production plan, offline product details, OQC sampling results, WMS collects and records the inbound products through the acquired data, and conducts quality status of the products in the warehouse through OQC sampling results. Update, when the quality check is OK, it can be automatically assigned for export.

WMS communicates with the total control PLC: The total control PLC acts as a bridge between the WMS and the roller line PLC. It mainly collects, discriminates, and summarizes various information of the roller line, and finally sends it to the WMS. The WMS sends the information according to the obtained information. The information such as sealing and product crossing distribution is sent to the total control PLC, and then sent to the roller line PLC by the total control PLC to realize the corresponding action. When the outbound command of a certain model is generated, it will be sent to the total control PLC for a card type information. The total control PLC is sent to the central control, and the central control causes the card board machine to flow out the corresponding card board. 
WMS communicates with the fork AGV server: When the product reaches the corresponding crossing of the roller line, it will trigger the WMS to send the corresponding storage command to the fork AGV server. The fork AGV implements the corresponding command and sends the good to the corresponding location, and feedback to the current execution status of the WMS in real time (including starting the execution of the command, taking the good, and successfully placing the good).

WMS communicates with the palletizing machine: When the outbound command of a certain model is generated, the WMS will send it to the upper computer of the palletizing machine to encode the command information corresponding to the model to achieve correct palletizing.

\subsection{WMS Main Function}

WMS is written in C\#. The C\# programming language is a language developed specifically for .NET applications and is a perfect combination with the .NET framework. Visual C\#.NET brings together almost all the latest developments in software development and software engineering research. Such as object-oriented, type safety, component technology, automatic memory management, cross-platform exception handling, version control, code security management. It differs from some previous programming languages when designing and developing program interfaces. It not only has the characteristics of rapid development of Visual Basic, but also has the powerful functions of $\mathrm{C}++$ language. Its main features are as follows: Visual C\#.NET adopts visual programming method; Visual C\#.NET adopts object-oriented programming idea; Visual C\#.NET adopts event-driven programming mode; Visual C\#.NET provides powerful data Manage and access operational capabilities to develop and manage large databases. [5]

WMS is divided into 11 modules, and the main modules are: model management, warehouse management, communication, and task status.

The model management module is mainly responsible for the import of the storage model and its associated information, and the addition, deletion and modification of the storage model.

The warehouse management module mainly has six functions: manual storage, manual delivery, automatic storage, automatic delivery, table class to view the location status, and image class to view the location status, to realize the location allocation and location status monitoring of the product. .

The communication module mainly has four functions of connecting WCS, connecting AGVS, connecting the total control PLC, and connecting the Palletizer to realize real-time communication with each communication module.

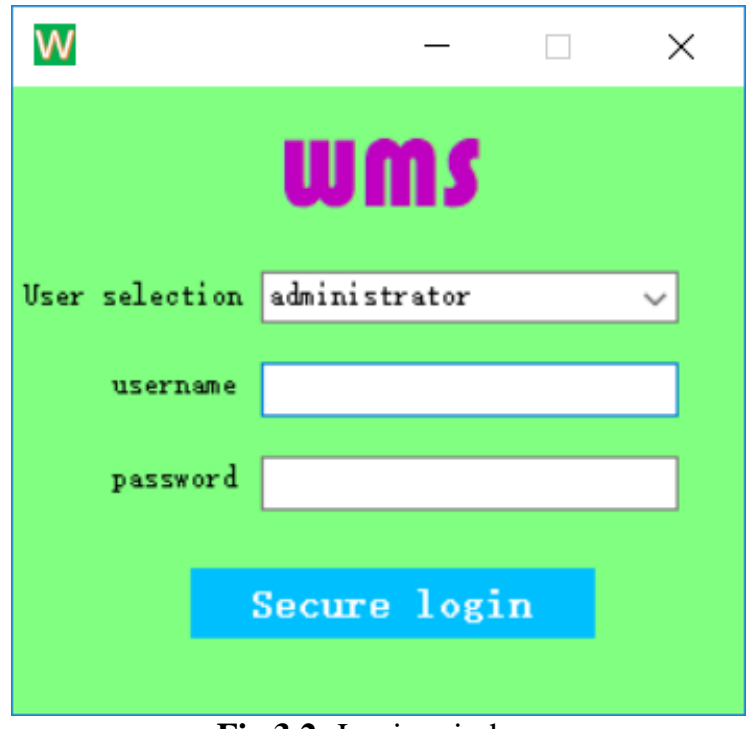

Fig 3.2: Login window

Fig- 3.2-3.5 shows some of the interfaces of WMS: 
WWardwe Msugenent Syatret

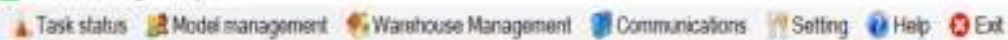

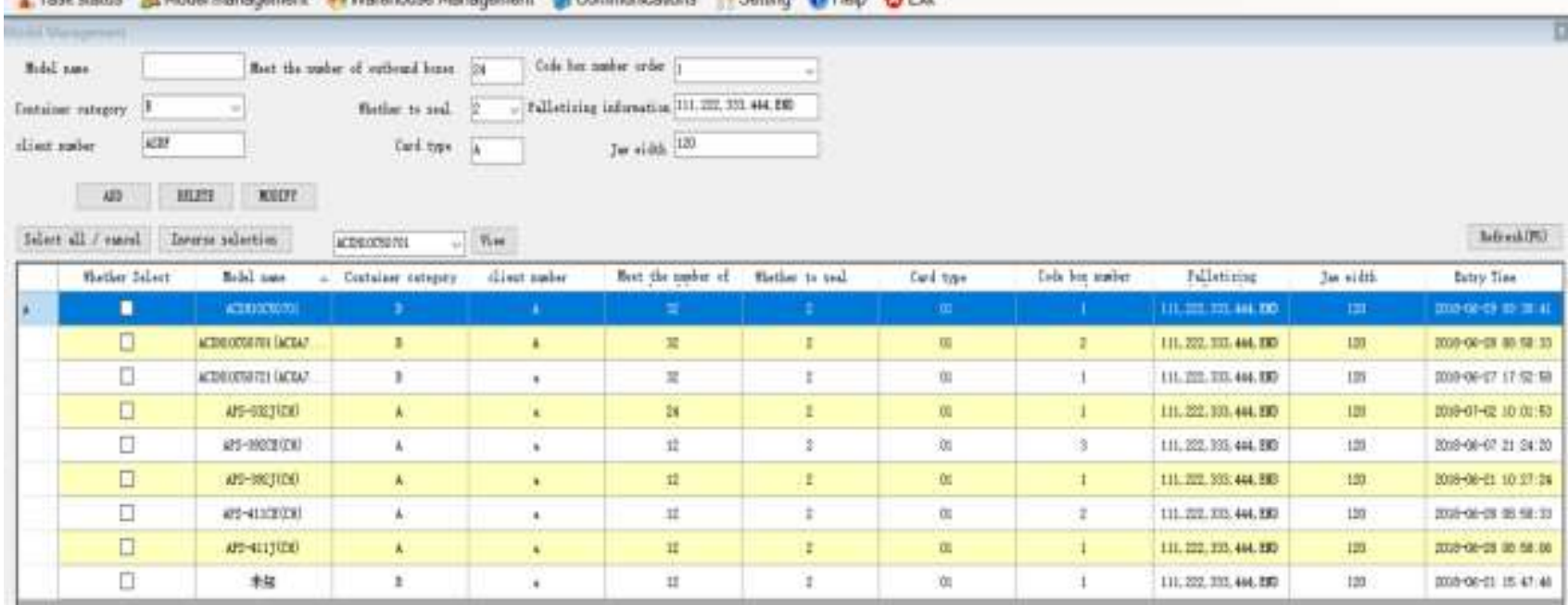

Currant otarage ratio: $120 / 2640$

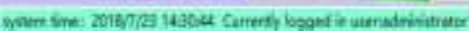

Fig 3.3: Model Management Interface

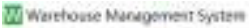

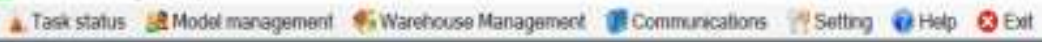

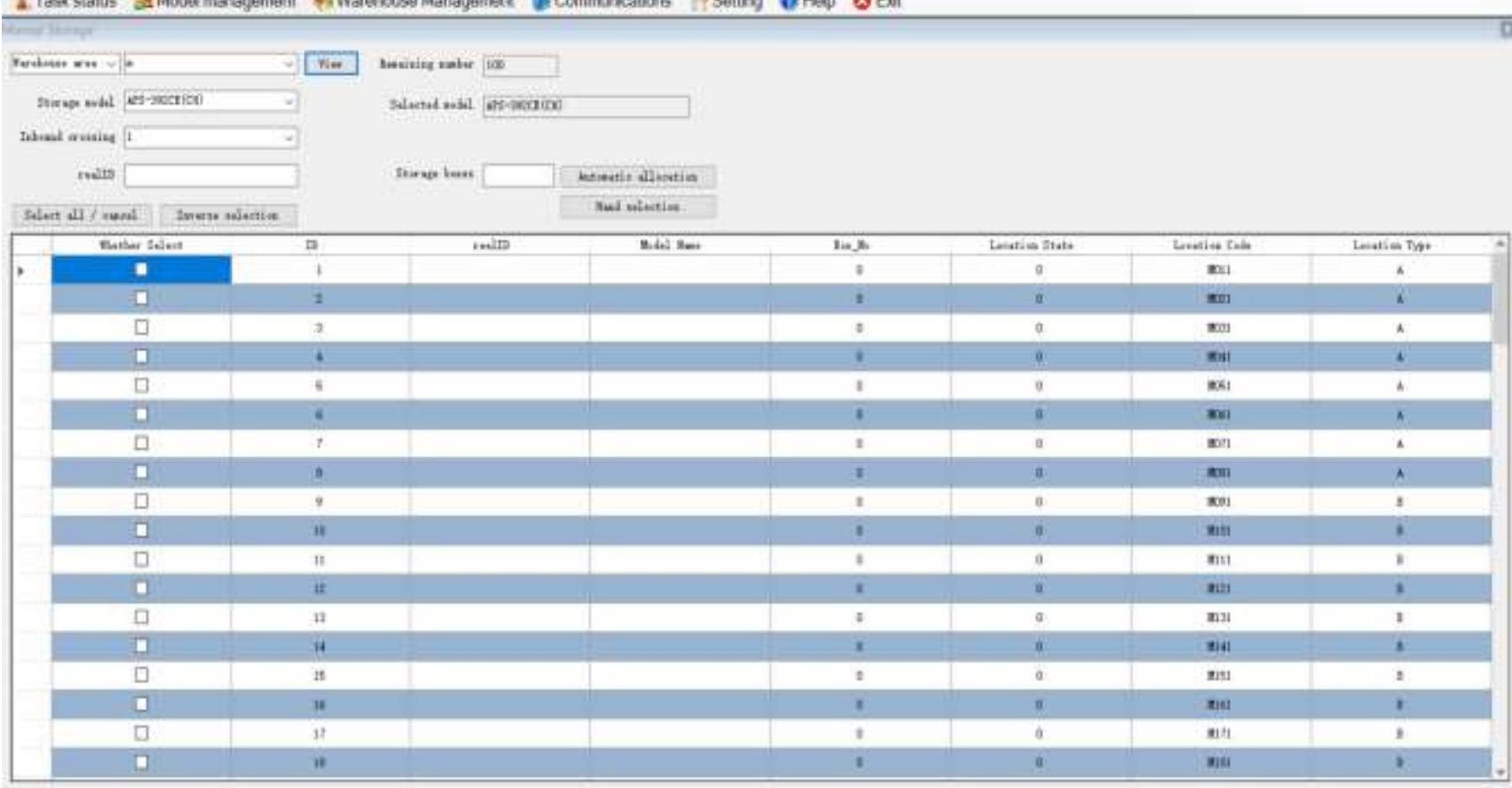

Currant utarase ratins: $120 / 2640$

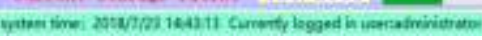

Fig 3.4: Manual Storage Interface 


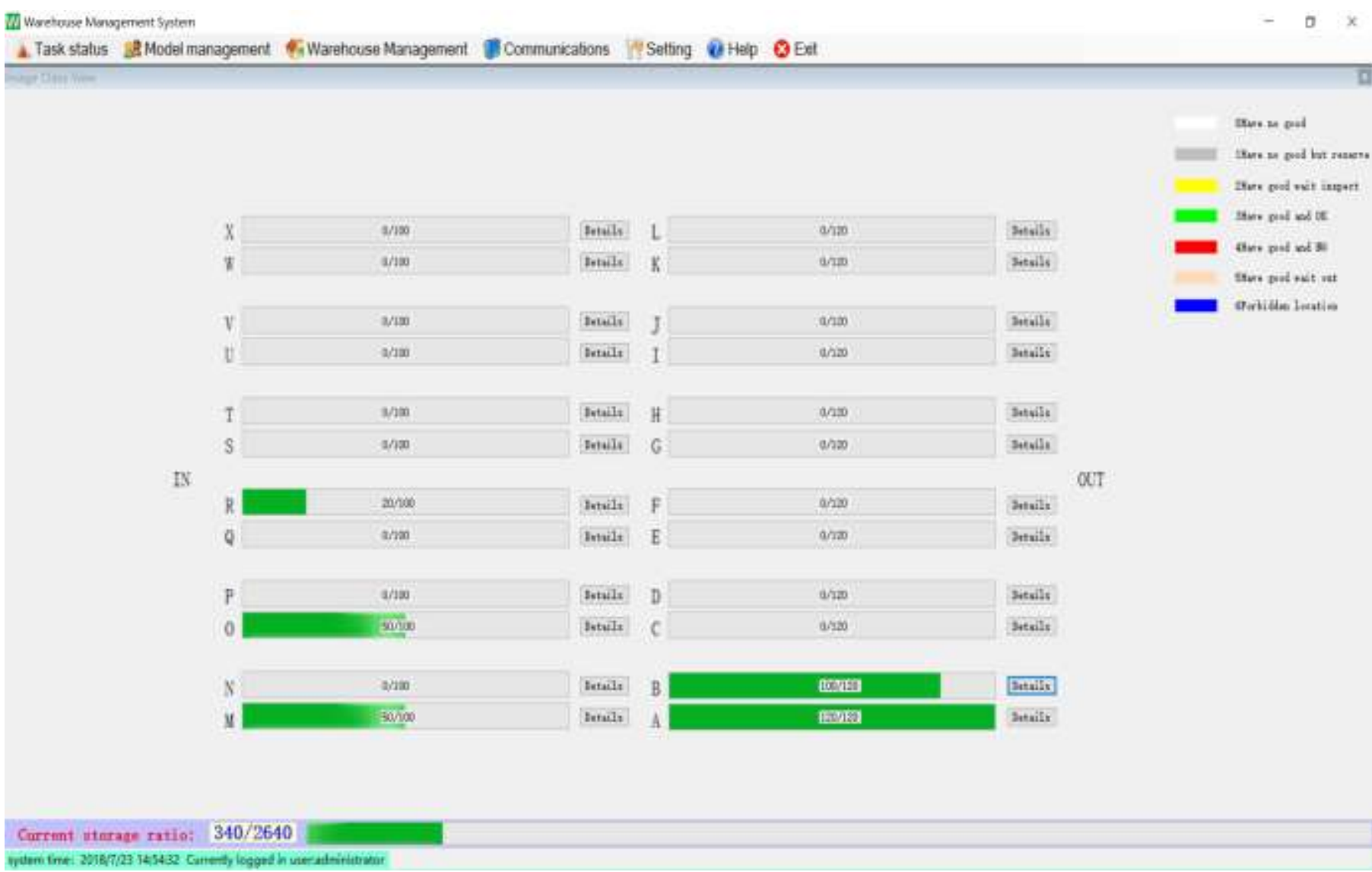

Fig 3.5: Image Class View Location Status Interface

\section{EXPERIMENT ANALYSIS}

After field testing, after entering the roller line from the offline product, WMS can correctly send the "No Sealing" or "Assigning the Inbound Dock Information" by scanning the code. When the designated crossing is reached, the corresponding task can also be sent to AGVS, and through the AGV pull goods to the corresponding location. When the goods is out of the warehouse, the WMS selects the corresponding product and the exit port, and sends the task to the AGVS. The AGV can correctly send the product to the corresponding exit crossing, and then the palletizer performs the corresponding palletizing action according to the instruction accepted from the WMS. Through testing, WMS can cooperate with other software and hardware to complete the automatic entry and exit of the product, without manual handling and palletizing, which greatly improves the efficiency of product in and out of the warehouse.

\section{CONCLUSION}

Through the development of WMS warehouse management system, and with WCS, roller line, palletizing machine, film machine, board warehouse machine, etc., real-time tracking and automatic storage of products can be realized, which greatly reduces the time of entering and leaving the warehouse. It reduces the mistakes that have been made by manual labor and has created economic value for the company. This WMS is different from the previous warehouse management system, and the application scenarios are different. The previous ones are used in the railcars, stacking and other warehouses, and this WMS conforms to the trend of the times, directly sends instructions to the AGV trolley to realize the automated inbound and outbound of goods. The WMS system has a lot of research space in the allocation of the location. When the location is further optimized, the speed of the inbound and outbound storage will be further improved, and the service life of the warehouse shelf can be improved. This is the direction that needs further research in the future.

\section{REFERENCES}

[1] Liu Xuejun, Li Chengyou. The automatic storage system keeps growing and ushers in greater opportunities $[\mathrm{J}]$. Logistics Technology and Applications, 2017, 22 (04): 57-59.

[2] Gan Zhongping.Automated warehousing system that keeps pace with the times[J].Logistics Technology and Application,2016,21(11):93-95.

[3] https://zh.wikipedia.org/wiki/\%E4\%B8\%BB\%E5\%B Е\%9E\%Е5\%BC\%8F\%Е6\%9E\%B6\%Е6\%A7\%8B,W ikipedia 
[4] https://baike.baidu.com/item/B\%2FS\%E7\%BB\%93\% $\mathrm{E} 6 \% 9 \mathrm{E} \% 84 / 4868588$ ?fromtitle=BS\&fromid=262911 7\&fr=aladdin\#3,Baidu Encyclopedia

[5] Xia Minjie, Luo Jing. Visual C\#.NET Foundation and Application Tutorial (2nd Edition). Beijing: Tsinghua University Press, 2017:2. 